\title{
Translation and validation of the Childbirth Experience Questionnaire (CEQ) into Sinhala Language in Sri Lanka
}

Malitha Patabendige ( $\square$ mpatabendige@gmail.com )

Teaching Hospital, Mahamodara https://orcid.org/0000-0002-4092-7092

Thilina S Palihawadana

University of Kelaniya Faculty of Medicine

Rasika P Herath

University of Kelaniya Faculty of Medicine

Prasantha S Wijesinghe

University of Kelaniya Faculty of Medicine

Research article

Keywords:

Posted Date: August 29th, 2019

DOI: https://doi.org/10.21203/rs.2.13302/v1

License: (c) (i) This work is licensed under a Creative Commons Attribution 4.0 International License.

Read Full License 


\section{Abstract}

Introduction The Childbirth Experience Questionnaire (CEQ) was initially produced to assess women's perceptions regarding their first birth experience. A robust validated instrument to evaluate first birth experience is currently lacking in Sri Lankan obstetric practice. Objectives Main objectives of our study were to adapt the CEQ among Sri Lankan Sinhala speaking women and to determine the psychometric properties of CEQ. This would yield an opportunity to evaluate childbirth experience among our women. Method Validation study was carried out by translating the English CEQ into Sinhala language following standard methodology comprising of forward and back translation. Total of 390 postpartum women were recruited through convenience sampling method at University Unit, North Colombo Teaching Hospital, Ragama, Sri Lanka, from February 2017 to January 2018. Initially CEQ was given to be completed four weeks after delivery and again two weeks postnatal. Mothers were asked to post the completed CEQ. Face validity was tested among twenty-five postnatal mothers and with seven labour ward staff members. Psychometric properties; internal consistency and validity of the CEQ were evaluated. Known-groups validation was used for construct validity. Results A total of $226(57.9 \%)$ of the recruited postnatal mothers completed the CEQ after one month postpartum. Face validity in Sri Lankan sample was demonstrated with all participants stating that CEQ was easy to understand and complete. Internal consistency was acceptable for the overall score $(0.85)$ and for all four domains in CEQ $(0.65$, $0.80,0.70,0.83$ for "own capacity", "professional support", "perceived safety" and "participation", respectively). Women with spontaneous onset of labour (except for "professional support" in women with spontaneous onset of labour) and women with a normal delivery showed significantly higher CEQ scores. However, oxytocin augmentation could not yield a difference in CEQ scores. A weighted kappa of 0.610.80 for all 22 items in CEQ demonstrated a good test-retest reliability. Conclusions This study shows that Sinhala version of CEQ can be used as a reliable and valid tool of childbirth experience among Sri Lankan Sinhala speaking women.

\section{Introduction}

The Childbirth Experience Questionnaire (CEQ) was derived and validated among first-time mothers in 2010 in Sweden ${ }^{1}$. It has been validated in UK in 2015 and Spain in 2016 also in Malaysia in $2017^{2,3,4}$. It measures four main domains of the woman's childbirth experience. Those are own capacity, professional support, perceived safety and participation, comprising of 22 items ${ }^{1,2}$. This CEQ is a simple self-administered questionnaire to assess satisfaction of women in different aspects of their first labour and birth 1. However woman's perceptions and experiences in childbirth are being rarely 
evaluated. Moreover, primiparous women are prone to get negative childbirth experiences 1,2 .

Since there is no properly validated instrument in Sinhala language to assess childbirth experience in Sri Lankan Sinhala speaking women, Sinhala CEQ may possibly be a worthwhile effort. Latest NICE guideline on intrapartum care has also highlighted that any research on the effectiveness of interventions in latent stage of labour needs measuring woman's satisfaction with childbirth experience ${ }^{5}$. In a similar manner for any study investigating woman's satisfaction with her birth experience in Sri Lanka needs to have a standardized method like CEQ. Validation of this tool is important in future research, audit projects as well as in service evaluation. Different tools to assess maternal childbirth experience are essential to identify those who need psychological and moral support. Therefore, this tool can be used to assess different dimensions of childbirth experience among primiparous women ${ }^{1}$.

The birth of a child is a significant event in a woman's life and family. Labour room staff should always try to make her labour experience as comfortable and dignified as possible. Although women seem to be satisfied with a healthy baby, the childbirth also has a psychological dimension ${ }^{6,7}$. Address of these hidden aspects is important for a positive childbirth experience and mother's long-term well-being 6,7. Midwives are doing a wonderful job with labouring women and helping them to achieve a satisfactory birth experience ${ }^{7}$. Higher workload in the hospitals resulted a sub-standard level of intrapartum care during childbirth ${ }^{7}$. Studies have reported that mothers often felt alone and unsupported during childbirth process and some of them would not get pregnant again due to the negative experience they had during last childbirth ${ }^{7}$. In the latest Cochrane review on continuous support for women during childbirth has reported that continuous labour support with the help from a labour companion (doula) who is a member of the labouring woman's social network, has been proved to effective in improving laboring women's satisfaction and hence their childbirth experience ${ }^{8}$. Thus it elaborates the significance of 
woman's psychological well-being and achieving a satisfactory childbirth experience in addition to birth of her baby.

The quality of intrapartum care that a particular woman gets has an impact on her physical and emotional well-being ${ }^{5}$. It has both short-term and longer-term effects including care towards the newborn ${ }^{5}$. Good communication with woman, support from labour ward staff and having woman's wishes respected, can enhance her confidence contributing to make a positive childbirth experience ${ }^{5}$. Negative experiences coming from their first childbirth can increase the risk of postpartum depression. It may give rise to a negative attitude in future pregnancies and childbirth too prompting women to request elective caesarean section ${ }^{9}$.

With regards to the other similar tools available, the 3-item Patient Perception Score (PPS) has three questions and these are rated on a 5-point Likert scale: "I felt I was treated with respect by the doctor(s)"; "I felt safe at all times"; "I felt well informed due to good communication with the doctor(s)" ${ }^{10}$. The PPS has been validated in UK population and it covers communication, respect and safety ${ }^{10}$. However, it measures experience of an operative delivery, not all aspects of labour and childbirth leading to multidimensional nature of maternal satisfaction ${ }^{2,10}$. Other birth satisfaction tools which have been developed and validated for the UK population include the Perceptions of Care Adjective Checklist Revised (PCACL-R) ${ }^{11}$. But in this PCACL-R validation, criterion validity, content validity and test-retest reliability were not measured ${ }^{25}$. In India there is a validated Hinditranslated scale for measuring maternal satisfaction is available ${ }^{12}$. In Sri Lankan context, currently we do not have a validated tool to assess birth satisfaction of our women.

General Objective was to translate and validate the CEQ from English language to the cultural context and lifestyle related to the Sinhala language. Sinhala language is one of the mainly used languages in Sri Lanka. Specific objectives were to conduct a linguistic translation, to conduct a validation study and to assess the psychometric properties of the Sinhala version of the CEQ. 


\section{Materials And Methods}

\section{Design and setting}

A validation study was carried out to translate and validate the CEQ from English to Sinhala at Ward 25 of University Unit of Obstetrics and Gynaecology, North Colombo Teaching Hospital (NCTH), Ragama, Sri Lanka, from February 2017 to January 2018. The original English language CEQ was translated into Sinhala language according to the standard validation protocols before its final validation study as recommended by the World Health Organization (WHO) ${ }^{13}$.

\section{Study population and sample size}

Mothers who have undergone their first labour and childbirth experience in last 24-48 hours during the study period was invited to participate in the study. Subjects to control ratio of 1:1 was taken using known-groups validation. Subjects were women who were nulliparous and undergoing operative deliveries (forceps deliveries, vacuum deliveries, emergency caesarean deliveries). Controls were women who were nulliparous and undergoing normal deliveries. According to the accepted method of 10 times the observed variables (subject to variable ratio of 10:1) minimum sample size of 220 with 22 items was taken ${ }^{1,14}$. CEQ has 22 items in four domains. As mentioned above those are: own capacity, professional support, perceived safety and communication. A $70 \%$ response rate was reported in the Swedish original CEQ development and validation study ${ }^{1}$. Therefore, it was decided to recruit a sample of postpartum women until the final minimum sample of 220 postpartum women (with completed questionnaires) have been responded depending on our response rate. Convenience sampling method was adopted.

\section{Inclusion and exclusion criteria}




\section{Inclusion criteria}

1. Pregnant women who were more than 16 years of age and mothers who have undergone their first labour and childbirth experience in last 24-48 hours.

2. Women with a single live fetus and who were labouring at term (including women who were having a caesarean delivery in their latent phase of labour and also women with failed induction of labour).

3. Women who were sending from labour room and undergoing emergency cesarean deliveries in last 24-48 hours were also included.

\section{Exclusion criteria}

1. Women who were having a baby who was not alive anymore or women with their babies were getting admitted to a special baby unit (e.g. Neonatal Special Care Baby Unit or Intensive Care Unit).

2. Patients who were not willing to participate, who could not read or write in Sinhala language were excluded from the study.

3. Women who were undergoing planned elective cesarean deliveries.

4. Women who were not educated up to G.C.E. Ordinary Level were also excluded.

\section{Translation process}

The linguistic translation process was carried out involving following basic steps ${ }^{15}$. Literal translation (forward translation) and adaptation of the English questionnaire into Sinhala 
lifestyle and cultural context were undertaken by two accredited bilingual native Sinhala speakers. One of them was a woman in reproductive age. After receiving the both Sinhala translations, our research group at Ragama, compared them. Discussion with obstetricians, labour room staff and patients as to whether the questionnaire measures what it was designed to measure and that clinically meaningful aspects were not lacking. With their comments, the Sinhala version of questionnaire was revised and rephrased according to Sri Lankan cultural and language context and compiled them into one Sinhala language version. It was also reviewed by the above accredited translators. Back-translation from Sinhala to English was performed by a single accredited translator who was also a bilingual native speaker. Then, review of the back-translation was carried out by the CEQ team at the Sahlgrenska Academy, University of Gothenburg, Sweden. The final Sinhala CEQ translation was produced after modifications, re-translation of necessary items to balance the discrepancies during translation process. Validation study was carried out using this final translation. During the literal translation we asked from the translators to give us options if there are different ways to translate any of the items and/or there are difficulties in the translation process.

\section{Study instrument}

Sinhala version of the CEQ was used as the study instrument. The CEQ consists of 22 items referring to the childbirth experience (Table 2). Women's responses to 19 items in CEQ were rated on a 4-point Likert scale and remaining 3 items were evaluated by means of a visual analogue scale (VAS). These VAS scores are then converted into categorical variables facilitating interpretation and analysis; $0-40=1,41-60=2,61-80=3$ and 81$100=4$. As mentioned in Table 2, negatively worded items were reversed. All 22 items in CEQ are divided into 4 groups as 4 main domains as mentioned above; "own capacity" (8 items about sense of control, their feelings during birth process and labour pain; $1,2,4,5,6,19,20,21$ items), "professional support" (5 items regarding information and the midwifery care they received; 13,14,15,16,17 items), "perceived safety" (6 items about sense of security and memories from their labour and childbirth; 3,7,8,9,18,22 items), and 
"participation" (3 items about own possibilities to influence maternal position, their movements and pain relief in labour; 10,11,12 items).

\section{Data collection procedure}

Eligible women were identified in the postnatal ward by the investigator and were invited to participate. They were given the information sheets and consent forms. Those who agreed to join recruited by signing an informed written consent form. Women were received a clear description of the procedure by the investigator. Initially basic demographic and clinical details were collected into a data collection sheet.

Two copies of CEQ with two stamped-envelopes were given to each mother and were asked to fill each in one moth postnatal and six weeks postnatal. Soon after childbirth, mothers were supposed to have gone through their first labour experience and having relatively fresh memories of their childbirth experience. As well as, mothers have minimum contact with their childbirth caregivers at hospital after four weeks. Therefore chances of giving socially desirable responses were minimal and minimizing potential bias. Recruited women were offered the option of completing the CEQ at home and sending it via post and also to ask for clarifications by making a phone call to the investigator. Reminders were sent after one moth and six weeks as a phone call or a post card. Demographic details and their delivery details were collected from the clinical notes.

\section{Data analysis}

Basic demographic characteristics of the data was analysed to see any deviations. Continuous variables were presented as means and standard deviations. Pearson Chi-

Square test was applied to any difference between categorical variables. Mann- Whitney U test was applied to compare any skewed continuous variables. $\mathrm{P}$ value $<0.05$ was considered as statistically significant.

\section{Face validity}


Face validity was done for the Sinhala CEQ version to see the items were well understood and easy to answer to. This was done by giving questionnaire to 25 primiparous mothers to find any difficult questions and asking their comments on questionnaire items. The CEQ was also given to a group of labour ward staff members at NCTH $(n=10)$ consisting of three experienced nurse-midwives, three midwives and one medical officer who was also a female in reproductive age group.

\section{Internal consistency}

This was evaluated using Cronbach's coefficient alpha. Usually, Cronbach's alpha $\geq 0.7$ is considered as a satisfactory level of internal consistency.

\section{Construct validity}

Construct validity was evaluated as follows. The first was whether the questionnaire was able to differentiate between complicated (operative) and uncomplicated (normal delivery) deliveries, and secondly to test questionnaire against the delivery outcome. The method of known-groups validation was used to measure construct validity. This method can be used to evaluate the ability of the CEQ to distinguish between above known groups within the sample and which were known to differ on known key socio-demographic or clinical variables. The CEQ has shown good construct validity and reliability for assessing childbirth experience between its known groups ${ }^{1}$.

A comparison was done between CEQ subscale scores and overall CEQ score for different key characteristics.

For example,

1. Women who had labour onset; spontaneous versus induced

2. Women with duration of labour; more than 12 hours versus less than 12 hours

3. Women with augmentation of labour; with oxytocin versus without oxytocin

4. Women who had a; normal delivery versus operative delivery. 
Here the overall CEQ score means average of the 4 individual CEQ subscale scores. It is well-documented that oxytocin augmentation of labour with oxytocin, operative delivery (instrumental or caesarean delivery) and long duration of labour ( $>12$ hours) known to cause a negative influence on woman's childbirth experience $16,17,18$.

Since the subscale scores were not normally distributed, non-parametric Mann-Whitney U test was applied to compare subscale scores between subgroups.

\section{Test-retest reliability}

To assess stability (test-retest reliability) a two-week test-retest analysis of the sample was

done. This agreement was further assessed by using the weighted Kappa (k) statistic ${ }^{19}$. To represent a substantial agreement between the two scores between one month and six weeks questionnaires a value of weighted Kappa between $0.61-0.80$ was taken ${ }^{20}$.

\section{Ethical considerations}

Eligible patients were identified and counseled by investigator at the study setting. Before entry into the study the investigator explained each patient the objectives, methods as well as potential benefits and risks of participating in the study. Patient information sheets were distributed to eligible patients. After sufficient information, informed written consent was obtained. 
We have also taken written permission from the original authors of CEQ, Dencker et.al in the CEQ team at the Sahlgrenska Academy, University of Gothenburg, Sweden.

Ethical aspects of this study were reviewed and approved by the Ethical Review Committee, Faculty of Medicine, University of Kelaniya, Ragama, Sri Lanka.

\section{Results}

\section{Characteristics of the participants}

Of the 390 eligible post-partum women who met the inclusion criteria, 226 (57.9\% response rate) women had completed and returned the first CEQ between one and four months after delivery. However, 12 questionnaires were incomplete and excluded from analysis giving rise to the final sample size of 214 for the analysis. Only 90 women (23.1\% response rate) returned the second CEQ. Basic demographic and clinical characteristics of the sample have been included in Table 1. Women with higher level of education (G.C.E. Advanced Level passed and above) are have a statistically significant better response rate compared to women educated up to G.C.E. Ordinary Level ( $p$ value $<0.05$ ). Unemployed women were also showed a statistically significant better response rate compared to unemployed women ( $p$ value < 0.05). However, level of income, mode of delivery and mode of onset of labour did not show any significant impact on the response rate. Table 2 shows the CEQ item description with mean score for each 22 items and also test-retest reliability (weighted Kappa scores) between first and second CEQ.

Table 1: Basic demographic and clinical characteristics of the study participants. 
Characteristics of the study participants $(n=214)$

Variables

Education

G.C.E. O/L passed

G.C.E. A/L passed

Diploma/University degree

Employed

Monthly income in LKR

Less than 20,000

Between 20,000-60,000

More than 60,000

Maternal age in years, mean (SD)

Gestational age in weeks, mean (SD)

Onset of labour

Spontaneous

More than 12 hours of labour duration

Type of delivery

Normal delivery

Forceps delivery

Vacuum delivery

Caesarean delivery

Perineal status after birth

Third/fourth degree tears n (\%)

$105(49.1)$

84 (39.3)

25 (11.6)

$64(30.0)$

$2(0.9)$

173 (80.8)

39 (18.2)

$28.7(4.5)$

$39.5(1.2)$

$121(56.5)$

$2(0.9)$

$162(75.7)$

$5(2.3)$

$10(4.7)$

37 (17.3)

$2(0.9)$

G.C.E. O/L: General Certificate of Education Ordinary Level, G.C.E. A/L: General Certificate of Education Advanced Level, LKR: Sri Lankan Rupees, SD: Standard Deviation.

Face validity 
Twenty-five women in the postnatal ward were invited to read the CEQ and were then inquired for any questions about it. A group of labour ward staff were also revealed only few modifications. Otherwise all postpartum women $(n=25)$ and staff members $(n=7)$ mentioned that the questionnaire was easy to understand and complete, in addition to suggesting some modifications. No respondents mentioned that any of the CEQ items should be removed and all agreed that none of the questions were upsetting or offensive concluding a good face validity.

\section{Internal consistency}

Internal consistency of our CEQ was $0.65,0.80,0.70$ and 0.83 for respective 4 domains such as "own capacity", "professional support", "perceived safety" and "participation". The overall Cronbach's alpha was 0.85 as in Table 4. Cronbach's alpha for all of the four subscales in the initial Swedish study validating the original CEQ in a Swedish population has mentioned for comparison in same Table 3.

Table 3: Cronbach's alpha for the subscales and for the overall scale of the CEQ.

\begin{tabular}{|c|c|c|c|c|}
\hline Domain & $\begin{array}{c}\text { Number of } \\
\text { items }\end{array}$ & & $\begin{array}{l}\text { lpha in our } \\
\text { y }\end{array}$ & $\begin{array}{c}\text { Cronbach's alpha from Swedish } \\
\text { study }{ }^{1}\end{array}$ \\
\hline \multicolumn{2}{|c|}{ Own capacity } & 8 & 0.65 & 0.82 \\
\hline \multicolumn{2}{|c|}{ Professional support } & 5 & 0.80 & 0.88 \\
\hline \multicolumn{2}{|c|}{ Perceived safety } & 6 & 0.70 & 0.78 \\
\hline \multicolumn{2}{|c|}{ Participation } & 3 & 0.83 & 0.62 \\
\hline \multicolumn{2}{|c|}{ Total scale } & 22 & 0.85 & \\
\hline
\end{tabular}

\section{Construct validity}

Known-group validation was applied to assess construct validity and details have been summarized in Table 4. Only two women had labour duration more than 12 hours and 
therefore labour duration was not taken into account in known-group validation. Women with spontaneous onset of labour and normal delivery groups obtained significantly higher CEQ scores, when compared to women whose labour had been induced and who had an instrumental delivery, respectively. Women who had a spontaneous onset of labour obtained statistically significantly higher scores in each of the following subscales: "own capacity", "perceived safety", "participation" and overall CEQ score, except for "professional support". Women who had a normal delivery obtained statistically significant higher scores than mothers with an instrumental delivery, for all four subscales including "own capacity", "professional support" "perceived safety" and "participation", as well as for the overall CEQ score.

However, no statistically significant differences were seen for any of CEQ subscales and overall score with regards to labour augmentation with Oxytocin as shown in Table 4.

Table 4: Difference between subscale scores and overall score of the CEQ in contrast to known groups: Construct validity. 


\begin{tabular}{|l|l|l|l|l|l|}
\hline \multicolumn{1}{|c|}{ CEQ score } & $\begin{array}{l}\text { Own } \\
\text { capacity }\end{array}$ & $\begin{array}{l}\text { Professional } \\
\text { support }\end{array}$ & $\begin{array}{l}\text { Perceived } \\
\text { safety }\end{array}$ & Participation & $\begin{array}{l}\text { Overall } \\
\text { CEQ } \\
\text { Score }\end{array}$ \\
\hline $\begin{array}{l}\text { Spontaneous onset of } \\
\text { labour n=121 }\end{array}$ & $\begin{array}{l}2.96 \\
(0.42)\end{array}$ & $3.37(0.52)$ & $3.26(0.54)$ & $2.57(0.95)$ & $\begin{array}{l}3.08 \\
(0.42)\end{array}$ \\
\hline $\begin{array}{l}\text { Induction of labour } \\
\mathbf{n = 9 3}\end{array}$ & $\begin{array}{l}2.87 \\
(0.45)\end{array}$ & $3.33(0.66)$ & $3.09(0.52)$ & $2.35(0.92)$ & $\begin{array}{l}2.96 \\
(0.43)\end{array}$ \\
\hline a p-value & 0.04 & 0.86 & 0.009 & 0.04 & 0.01 \\
\hline $\begin{array}{l}\text { Effect size } \\
\text { No oxytocin } \\
\text { augmentation } \mathbf{n = 1 3 7}\end{array}$ & $\begin{array}{l}2.95 \\
(0.36)\end{array}$ & $3.34(0.57)$ & $3.21(0.49)$ & $2.39(0.95)$ & $\begin{array}{l}3.03 \\
(0.37)\end{array}$ \\
\hline $\begin{array}{l}\text { Oxytocin augmentation } \\
\mathbf{n}=\mathbf{7 7}\end{array}$ & $\begin{array}{l}2.87 \\
(0.55)\end{array}$ & $3.36(0.62)$ & $3.15(0.64)$ & $2.63(0.90)$ & $\begin{array}{l}3.02 \\
(0.52)\end{array}$ \\
\hline a p-value & 0.49 & 0.54 & 0.18 & 0.11 & 0.59 \\
\hline Effect size & 0.05 & 0.04 & 0.001 & 0.12 & 0.04 \\
\hline Normal delivery $\mathbf{n}=162$ & $\begin{array}{l}3.05 \\
(0.36)\end{array}$ & $3.49(0.55)$ & $3.29(0.40)$ & $2.56(0.93)$ & $\begin{array}{l}3.15 \\
(0.33)\end{array}$ \\
\hline $\begin{array}{l}\text { Operative delivery } \\
\mathbf{n = 5 2}\end{array}$ & $\begin{array}{l}2.69 \\
(0.54)\end{array}$ & $3.17(0.68)$ & $3.03(0.65)$ & $2.26(0.84)$ & $\begin{array}{l}2.83 \\
(0.53)\end{array}$ \\
\hline a p-value & 0.001 & 0.01 & 0.04 & 0.01 & 0.005 \\
\hline Effect size & 0.34 & 0.27 & 0.19 & 0.18 & 0.3 \\
\hline
\end{tabular}

Data has presented as mean (SD). ${ }^{a}$ Mann-Whitney U-test was used to compute p-values as the scores were not parametrically distributed. Operative delivery consists of caesarean and instrumental deliveries. Overall score for the CEQ is the mean score of its 4 subscales. CEQ: Childbirth Experience Questionnaire.

Test-retest reliability 
There were 90 respondents who returned both the first and second CEQ. For these 90 respondents the quadratic weighted index of agreement (weighted Kappa) for each of the 22 CEQ items was calculated and presented in Table 2. All 22 items of the CEQ were found to have a considerable agreement between the scores gained at one month and then six weeks postnatal respectively. Therefore, the CEQ can be considered as a very reliable instrument when used on separate occasions.

\section{Discussion}

This study describes a successful transcultural adaptation of the CEQ into Sinhala language in Sri Lankan context. According to our study, the Sinhala version of the CEQ has shown most of the psychometric properties to the original Swedish as well as adapted English and Spanish versions ${ }^{3}$. It is therefore suitable to assess childbirth experience in Sinhala speaking Sri Lankan postnatal mothers after their first childbirth.

To improve maternal healthcare services in a society, mothers' opinions and expectations should be taken into account ${ }^{21,22}$. Larkin et al., further elaborates that identification of the core attributes of the labour/childbirth experience might yield a framework for future planning and considerations ${ }^{22}$. These type of tools such as CEQ can help to improve maternal health services in order to tailor women's expectations in labour and childbirth process. Disrespectful maternity care is prevalent in many settings throughout the globe, particularly in under-resource settings. This violates their human rights as well as acts as a significant barrier for the access of safe intrapartum care services ${ }^{23}$. Latest WHO intrapartum care recommendations targeting a positive childbirth experience elaborate this 
furthermore ${ }^{24}$. To uplift the quality of care in maternal health care several new strategies are coming up in Sri Lanka such as WHO Safe Childbirth Checklist 25, 26, 27 . Research on birth experience is limited. This assessment tool of childbirth experience (CEQ) may help to provide a positive impact in Sri Lanka. With postal method of sending the questionnaires, we could achieve a 226 women giving rise to a response rate of $57.9 \%$. However, this is well below what was seen at Swedish study (70\%) and Spanish validation (62\%), but comparable to UK study (59\%) ${ }^{1,2}$. In Malaysian study the response rate has not mentioned 20.

Our CEQ demonstrated a high face validity. We found a good internal consistency with Cronbach's alpha $\geq 7$ for three out of four domains and overall CEQ score as shown in Table 3. Dencker et al., in their original Swedish study, found significant differences when comparing women with labour lasting less than 12 hours, women with no labour augmentation using oxytocin and normal delivery, versus women with more than 12 hours of labour, augmentation with oxytocin and instrumental delivery, respectively, for all four domains ${ }^{1}$. However in our study, this known-group validation showed validity of the CEQ in normal delivery versus instrumental delivery and spontaneous onset of labour versus induced labour groups. These were almost in the similar way as for the initial Swedish study ${ }^{1}$ and similar to the UK as well as Spanish adaptations ${ }^{2,3}$. However, we could get only two women with more than 12 hours of labour duration. Therefore, this was not included in analysis although others have done this ${ }^{2,3}$. Our study also could not demonstrate any significant difference in CEQ scores between augmentation of labour with oxytocin versus no oxytocin augmentation. It worthwhile to mention that oxytocin infusions are commonly used in Sri Lankan labour wards for the majority of women in labour. No difference between oxytocin augmentation and no oxytocin possibly may be due to this high oxytocin use. Small effect sizes were seen in overall CEQ score across all known groups (Table 4). In Malaysian adaptation of CEQ, construct validity has been evaluated using confirmatory factor analysis, not with known group validation as mentioned above ${ }^{4}$. We 
had only two third/fourth degree perineal tears and therefore it was not included in construct validity.

Requesting to send the questionnaires back through email is difficult in our setting which was done in UK study ${ }^{2}$, so we decided to have them posted instead which was also used in Spanish study ${ }^{3}$. According to the latest perinatal health reports in Europe; Sweden, UK and Spain have far superior maternal and perinatal statistics compared to Sri Lanka ${ }^{28}$. These might also have influenced on the maternal birth experience and giving quite lower values in our setting comparatively. Some authors propose hypotheses that excessive interventions could compromise birth satisfaction leading to the difficulty of making a more accurate comparison between studies ${ }^{29}$. Although original CEQ was developed for mothers after their first childbirth, Spanish CEQ validation study found a novel thing that CEQ can also be used for multiparous women ${ }^{3}$. They have also showed that the Spanish adaptation could discriminate birth experience between primiparous and multiparous women as a test for construct validity ${ }^{3}$. We found the lowest mean CEQ score as 1.6 for the item 20 ("Experienced level of labour pain"). It also had a good stability (kappa 0.66). This signals that more emphasis has to be paid on labour analgesia.

CEQ comprises of 22 items and a tool measuring women's' perception and experience of birth should ideally be a simplest possible way. The PPS which developed in UK in 2009 is a 3-item simple tool ${ }^{10}$. Being a simple short tool would largely have an impact on response rate, feasibility and generalizability of the measuring tool. However this PPS has been developed and validated only for the operative deliveries. Even though a relatively long questionnaire, our CEQ address the entire multidimensional picture of labour and childbirth. It is obvious that it might take about ten to fifteen minutes to complete the CEQ, but it still has a value in measuring maternal satisfaction not only in any type of delivery but also in a multidimensional picture regarding the process of labour and childbirth. The PCACL-R is also a valid tool to measure women's perception regarding labour and childbirth and it comprises of 16 items. However, as mentioned earlier this PCACL-R 
content validity, criterion validity and test-retest reliability has not been computed ${ }^{11}$. Maternal Satisfaction for Caesarean Section (MSCS) was designed to assess satisfaction of women undergoing caesarean deliveries under regional anaesthesia and its 22-item tool ${ }^{30}$. Although this can only be used for caesarean births, it has a good validity but a low reliability ${ }^{30}$. The Intrapartum care in relation to WHO recommendations (IC-WHO) is 63item questionnaire which has been prepared based on WHO intrapartum care recommendations ${ }^{31}$. But description of its psychometric properties is lacking ${ }^{31,32}$.

\section{Limitations}

This study is not without limitations. As previously mentioned, we could not get an adequate sample for women with more than 12 hours of labour duration and liberal use of oxytocin augmentation was an issue. Another limiting factor is getting accreted translated for this type of health-related studies. A recall of four to five months had to be done for some women even after monthly reminders were done as phone calls leading to the $57.9 \%$ response rate. We also had to exclude 12 questionnaire from analysis due to incomplete data. Furthermore, we could not compute criterion validity for our validation study due to unavailability of a 'gold standard' assessment of childbirth experience in Sri Lanka to be compared with. Time lapses between childbirth and questionnaire (from four weeks to fourfive months in some cases) could possibly give negative influence on birth experience of women as argued by some authors $33,34,35$.

\section{Conclusions And Recommendations}

As a conclusion, this study indicates that use of the Sinhala translation of the CEQ as a reliable and valid tool with well-preserved psychometric properties to assess childbirth experience among Sinhala speaking women in Sri Lanka. And also it could be used as a screening or a monitoring tool to identify those women with negative birth experience in different interventions or implementation programmes in maternal care settings. However, need of Tamil translation and validation of the CEQ is also important for betterment of 
assessing childbirth experience in Sri Lanka since Sinhala and Tamil languages are the two main languages in Sri Lanka.

\section{Declarations}

\section{Acknowledgements}

I would like to thank the CEQ team especially Prof. Anna Dencker, at the Sahlgrenska Academy, University of Gothenburg, Sweden for granting the opportunity to use their questionnaire and all the support given during the study. Moreover, I'm much grateful to all new mothers participated in this study.

\section{Abbreviations}

CEQ: Childbirth Experience Questionnaire

NICE: National Institute for Health and Clinical Excellence

UK: United Kingdom

PPS: Patient Perception Score

PCACL-R: Perceptions of Care Adjective Checklist Revised

NCTH: North Colombo Teaching Hospital

GCE: General Certificate of Education

VAS: Visual Analogue Scale

WHO: World Health Organization

MSCS: Maternal Satisfaction for Caesarean Section 
IC-WHO: Intrapartum care in relation to WHO recommendations

\section{Declarations}

- Ethics approval and consent to participate

Ethical aspects of this study were reviewed by the Ethical Review Committee of the Faculty of Medicine, University of Kelaniya, Ragama, Sri Lanka, which granted approval. Informed written consent will be taken from each participant before giving the questionnaire.

- Consent for publication

Not applicable

- Availability of data material

Data gathered from this study will be available upon a request from the first author (MP).

\section{- Competing interests}

The authors declare that they has no competing interests.

\section{- Funding}

No funding sources. Self-funded work by the authors.

\section{- Authors' contributions}


Conceived and designed the experiments: MP, TSP,PSW. Performed the experiments: MP. Analyzed the data: MP. Contributed reagents/materials/analysis tools: MP,TSP, RPH, PSW. Wrote the paper: MP,TSP, $\mathrm{RPH}, \mathrm{PSW}$. All authors read and approved the final manuscript.

\section{- Authors' information}

Dr. Malitha Patabendige: Registrar in Obstetrics and Gynaecology, University Obstetrics Unit, North Colombo Teaching Hospital, Ragama, Sri Lanka

Dr. Thilina S Palihawadana, and Dr. Rasika P Herath: Senior Lecturer, Department of Obstetrics and Gynaecology, Faculty of Medicine, University of Kelaniya, Ragama, Sri Lanka,

Prof. Prasantha S Wijesinghe: Senior Professor and Chair, Department of Obstetrics and Gynaecology, Faculty of Medicine, University of Kelaniya, Ragama, Sri Lanka.

\section{- Acknowledgements}

My sincere gratitude goes to the CEQ team especially Prof. Anna Dencker, at the Sahlgrenska Academy, University of Gothenburg, Sweden for granting the opportunity to use their questionnaire and all the support given during the study.

\section{References}

- Dencker A, Taft C, Bergqvist L, Lilja H, Berg M. Childbirth experience questionnaire (CEQ): development and evaluation of a multidimensional instrument. BMC Pregnancy and Childbirth. 2010; 10:81.

- Walker KF, Wilson P, Bugg GJ, Dencker A,Thornton JG. Childbirth experience questionnaire: validating its use in the United Kingdom. BMC Pregnancy and Childbirth 2015; 15:86. 
- Soriano-Vidal FJ et al., Spanish version of the Childbirth Experience Questionnaire (CEQ-E): reliability and validity assessment. BMC Pregnancy and Childbirth. 2016; 16: 372.

- Al-kubaisi Muna Kh, Radeef AS. Translation and Validation Study of the Malaysian Version of the Childbirth Experience Questionnaire - CEQ. Journal of International Dental and Medical Research 2018; 11(1): 357-361.

- National Institute for Health and Clinical Excellence. Intrapartum care of healthy women and babies NICE Clinical Guideline 190, 2014. Available at http://www.nice.org.uk/guidance/cg190 (Accessed 10 December 2018).

- Katie Cook, Colleen Loomis. The Impact of Choice and Control on Women's Childbirth Experiences. The Journal of Perinatal Education 2012; 21(3): 158-168.

- Larkin P, Begley CM, Devane D. 'Not enough people to look after you': an exploration of women's experiences of childbirth in the Republic of Ireland. Midwifery 2012; ;28(1):98-105.

- Bohren MA, Hofmeyr GJ, Sakala C, Fukuzawa RK, Cuthbert A. Continuous support for women during childbirth. Cochrane Database of Systematic Reviews 2017, Issue 7. Art. No: CD003766. DOI: 10.1002/14651858.CD003766.pub6. Available at 
https://www.cochranelibrary.com/cdsr/doi/10.1002/14651858.CD003766.pub6/full (Accessed 15 December 2018).

- Pang MW, Leung TN, Lau TaK, Hang Chung TK: Impact of first childbirth on changes in women's preference for mode of delivery: follow-up of a longitudinal observational study. Birth 2008, 35(2):121-128.

- Siassakos D et al., A simple tool to measure patient perceptions of operative birth. BJOG - an international journal of obstetrics and gynaecology. 2009; 116(13):1755-61.

- Redshaw M, Martin CR. Validation of a perceptions of care adjective checklist. Journal of evaluation in clinical practice. 2009;15(2):281-8.

- Jha P, Larsson M, Christensson K, Skoog Svanberg A. Evaluation of the psychometric properties of Hindi-translated Scale for Measuring Maternal Satisfaction among postnatal women in Chhattisgarh, India. PLoS One.2019 29;14(1): e0211364.

- World Health Organization. Process of translation and adaptation of instruments. Geneva: World Health Organization 2016. Available at: https://www.who.int/substance_abuse/research_tools/translation/en/ (Accessed on 0104-2018).

- Fayers P, Machin D. Quality of Life: Assessment, analysis and interpretation. John Wiley and Sons Ltd London, United Kingdom. 2000. 289-306. 
- Diane Wild et.al. Principles of Good Practice for the Translation and Cultural Adaptation Process for Patient-Reported Outcomes (PRO) Measures: Report of the ISPOR Task Force for Translation and Cultural Adaptation. Value Health 2005; 8(2): 94-104.

- Waldenstrom U, Hildingsson I, Rubertsson C, Radestad I. A negative birth experience: Prevalence and risk factors in a national sample. Birth 2004; 31(1): 17-27.

- Brown S, Lumley J. Changing childbirth: lessons from an Australian survey of 1336 women. British Journal of Obstetrics Gynaecology 1998; 105(2): 143-55.

- Nystedt A, Hogberg U, Lundman B. The negative birth experience of prolonged labour: a case-referent study. Journal of Clinical Nursing 2005; 14(5):579-86.

- Altman D. Practical statistics for medical research: Chapman and Hall/CRC; London, United Kingdom. 1990. 250-264.

- Landis JR, Koch GG. Measurement of Observer Agreement for Categorical Data. Biometrics. 1977; 33(1):159-74.

- Renfrew MJ, McFadden A, Bastos MH, Campbell J, Channon AA, Cheung NF, et al. Midwifery and quality care: findings from a new evidence-informed framework for maternal and newborn care. 2014; 384(9948):1129-45. 
- Larkin P, Begley CM, Devane D. Women's experiences of labour and birth: an evolutionary concept analysis. Midwifery. 2009;25 (2): e49-59.

- Bohren MA et al., Facilitators and barriers to facility-based delivery in low- and middleincome countries: a qualitative evidence synthesis. Reproductive Health. 2014;11(1):71.

- World Health Organization. WHO recommendations Intrapartum care for a positive childbirth experience 2018. Geneva: World Health Organization 2018. Available at: https://www.who.int/reproductivehealth/publications/intrapartum-care-guidelines/en/ (Accessed on 01-03-2019).

- Patabendige M, Senanayake H. Implementation of the WHO safe childbirth checklist program at a tertiary care setting in Sri Lanka: a developing country experience. $B M C$ Pregnancy and Childbirth. 2015;15: 12.

- Senanayake HM, Patabendige M, Ramachandran R. Experience with a context-specific modified WHO Safe Childbirth Checklist at two tertiary care settings in Sri Lanka. BMC Pregnancy and Childbirth. 2018; 1:411.

- Senanayake HM, Patabendige M, Ramachandran R. Piloting of WHO Safe Childbirth Checklist using a modified version in Sri Lanka. BMC Research Notes. 2018:14;11(1):896.

- Euro-Peristat Project. European Perinatal Health Report. Core indicators of the health and care of pregnant women and babies in Europe in 2015, November 2018. Available at: www.europeristat.com (Accessed 02-02-2019). 
- Christiaens W, Bracke P. Assessment of social psychological determinants of satisfaction with childbirth in a cross-national perspective. BMC Pregnancy and Childbirth. 2007; 7:26.

- Morgan PJ, Halpern S, Lo J. The development of a maternal satisfaction scale for caesarean section. International journal of obstetric anesthesia. 1999; 8(3):165-70.

- Sandin-Bojö AK, Larsson BW, Hall-Lord ML. Women's perception of intrapartal care in relation to WHO recommendations. Journal of Clinical Nursing. 2008; 17(22):29933003.

- Sawyer A et al., Measures of satisfaction with care during labour and birth: a comparative review. BMC Pregnancy and Childbirth. 2013; 13:108.

- Waldenström U. Why Do Some Women Change Their Opinion About Childbirth Over Time? Birth. 2010; 31:102-7.

- Waldenstrom U. Women's Memory of Childbirth at Two Months and One Year after the Birth. 2003; 30:248-54.

- Tinti C, Schmidt S, Businaro N. Pain and emotions reported after childbirth and recalled 6 months later: the role of controllability. Journal of Psychosomatic Obstetrics and Gynecology. 2011; 32:98-103.

\section{Table 2}


Table 2: Description of 22 items and scores in Childbirth experience questionnaire (CEQ). 


\begin{tabular}{|c|c|c|c|}
\hline Item in CEQ & $\begin{array}{l}\text { Total sample in } \\
\text { each item } \\
(n=214)\end{array}$ & $\begin{array}{l}\text { Mean } \\
\text { Score } \\
\text { (SD) }\end{array}$ & $\begin{array}{c}\text { Weighted } \\
\text { Kappa } \\
\text { scores between } \\
1^{\text {st }} \text { and } 2^{\text {nd }} \\
\text { CEQ }\end{array}$ \\
\hline 1. Labour progressed as I had expected. & 214 & 3.0 & 0.83 \\
\hline 2. I felt strong. & 214 & $(0.9)$ & 0.66 \\
\hline 3. I felt scared. & 214 & 3.4 & 0.74 \\
\hline 4. I felt strong capable. & 214 & $(0.6)$ & 0.76 \\
\hline 5. I felt strong tired ${ }^{\mathrm{R}}$. & 214 & 2.0 & 0.71 \\
\hline 6. I felt happy. & 214 & $(0.9)$ & 0.74 \\
\hline $\begin{array}{l}\text { 7. I have many positive memories from } \\
\text { the labour process. }\end{array}$ & 214 & $\begin{array}{l}3.5 \\
(0.6)\end{array}$ & 0.69 \\
\hline $\begin{array}{l}\text { 8. I have many negative memories from } \\
\text { the labour process }{ }^{R} \text {. }\end{array}$ & 214 & $\begin{array}{l}3.6 \\
(0.7)\end{array}$ & 0.67 \\
\hline 9. Some of my memories from the labour & 214 & $\begin{array}{l}3.6 \\
(0.7)\end{array}$ & 0.68 \\
\hline $\begin{array}{l}\text { process make me feel depressed }^{\mathrm{K}} \text {. } \\
\text { 10. I felt I could choose whether I should }\end{array}$ & 214 & $\begin{array}{l}3.4 \\
(0.9)\end{array}$ & 0.63 \\
\hline $\begin{array}{l}\text { be up and moving or lie down. } \\
\text { 11. I felt I could choose the delivery }\end{array}$ & 214 & 3.2 & 0.72 \\
\hline $\begin{array}{l}\text { position. } \\
\text { 12. I felt I could choose which pain relief }\end{array}$ & 214 & $(1.0)$ & 0.70 \\
\hline method to use. & 214 & 3.4 & 0.67 \\
\hline $\begin{array}{l}\text { 13. My midwife devoted enough time to } \\
\text { me. }\end{array}$ & 214 & $(0.9)$ & 0.71 \\
\hline $\begin{array}{l}\text { 14. My midwife also devoted enough time } \\
\text { to my partner. } \\
\text { 15. My midwife kept me informed about }\end{array}$ & 214 & $\begin{array}{l}2.3 \\
(1.1)\end{array}$ & 0.82 \\
\hline $\begin{array}{l}\text { what was happening during labour and } \\
\text { birth. }\end{array}$ & & 2.6 & \\
\hline 16. My midwife understood my needs. & 214 & (1.1) & 0.77 \\
\hline $\begin{array}{l}\text { 17. I felt very well taken care of by the } \\
\text { midwife. } \\
\text { 18. My impression of the medical }\end{array}$ & 214 & $\begin{array}{l}2.5 \\
(1.1)\end{array}$ & 0.66 \\
\hline competence made me feel secure. & 214 & 2.9 & 0.71 \\
\hline $\begin{array}{l}\text { 19. I felt that I handled the situation well. } \\
\text { 20. Experienced level of labour pain, VAS }\end{array}$ & 214 & $(0.9)$ & 0.65 \\
\hline $\mathrm{R}$. & 214 & 2.9 & 0.66 \\
\hline 21. Experienced level of control, VAS a. & 214 & $(0.9)$ & 0.68 \\
\hline
\end{tabular}




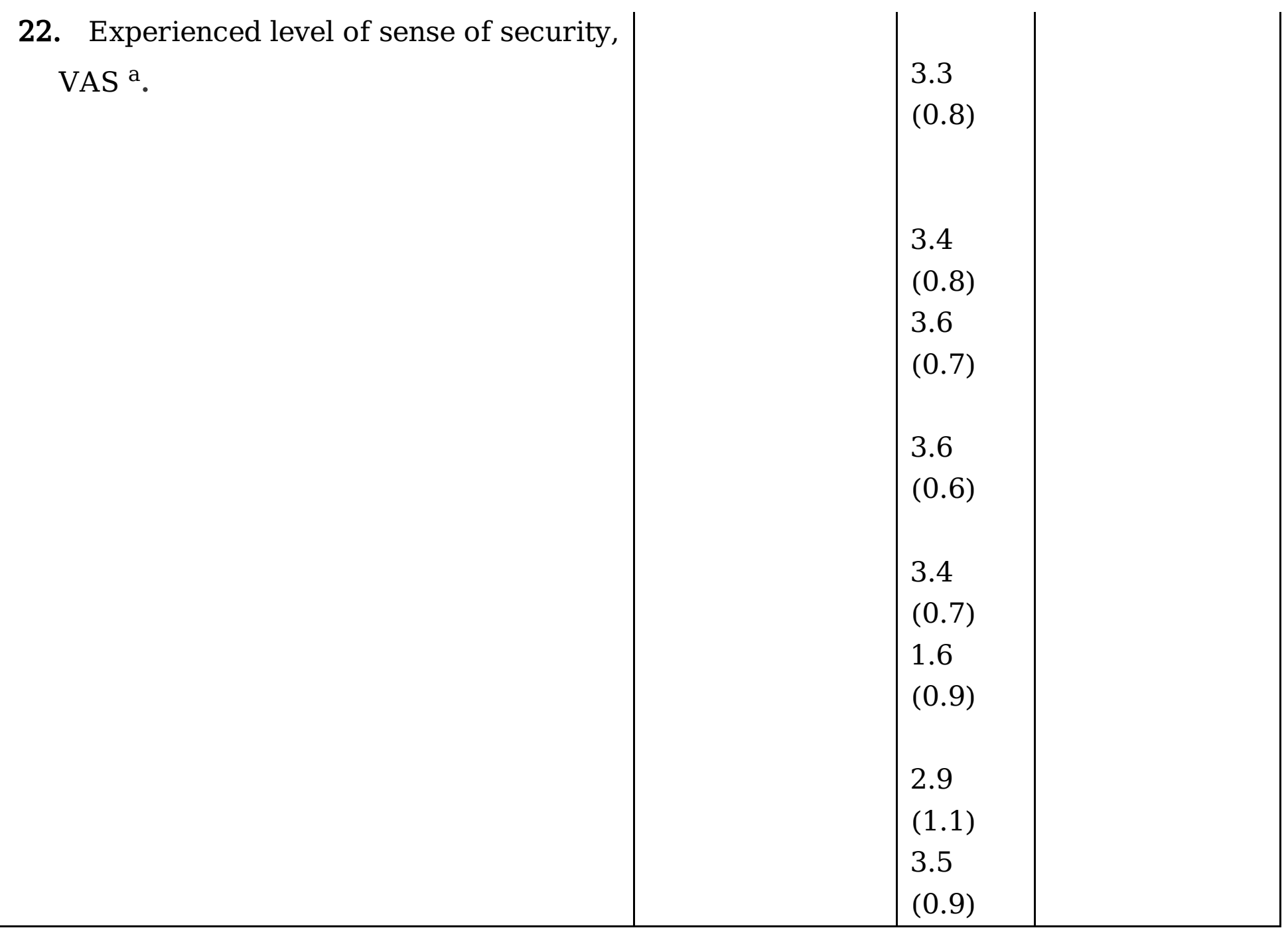

$\mathbf{R}$ Ratings of negatively worded statements are reversed.

a VAS-scales scores were recoded to categorical values, $0-40=1,41-60=2,61-80=3$ and 81-100 = 4. VAS: Visual Analogue Scale, CEQ: Childbirth Experience Questionnaire. 